\title{
Study on the Comprehensive Properties and Microstructures of A3-3 Matrix Graphite Related to the High Temperature Purification Treatment
}

\author{
Xiangwen Zhou $(\mathbb{D}$, Zhenming Lu $(\mathbb{D}$, Jie Zhang, Jing Song, Bing Liu, \\ Yaping Tang, and Chunhe Tang \\ Institute of Nuclear and New Energy Technology of Tsinghua University, Collaborative Innovation Center of Advanced Nuclear \\ Energy Technology, The Key Laboratory of Advanced Reactor Engineering and Safety, Ministry of Education, Beijing 100084, China
}

Correspondence should be addressed to Xiangwen Zhou; xiangwen@tsinghua.edu.cn

Received 29 November 2017; Accepted 18 January 2018; Published 26 February 2018

Academic Editor: Eugenijus Ušpuras

Copyright (c) 2018 Xiangwen Zhou et al. This is an open access article distributed under the Creative Commons Attribution License, which permits unrestricted use, distribution, and reproduction in any medium, provided the original work is properly cited.

\begin{abstract}
At the beginning, a comparative analysis was made on the oxidation corrosion rate and ash content of A3-3 matrix graphite (MG) pebbles lathed before and after high temperature purification (HTP) treatment. Their oxidation corrosion rate and ash contents were almost identical, which indicated that the HTP process was to purify the entire MG pebbles and not limited on the surfaces. Furthermore, the multiple mechanical and thermal properties of MG treated without and with the treatment of $\mathrm{HTP}$ at $\sim 1900^{\circ} \mathrm{C}$ were compared and their microstructure features were characterized as well. As the crush strength, oxidation corrosion rate, and erosion rate of MG without HTP treatment did not satisfy the specifications, the comprehensive properties and purity of MG with HTP were improved in various degrees through the HTP process so that all performances met the requirements of the A3-3 MG. The improvement of crush strength and erosion rate of MG in the HTP process could be mainly attributed to the upgradation of ordered microstructure and corresponding increase of density. However, the enhancement of oxidation corrosion rate was due to the synergistic effects of microstructural optimization and reduction of impurity elements, especially the transition metal elements of MG in the HTP process.
\end{abstract}

\section{Introduction}

Based on the rich design and construction experiences of HTR-10, the construction of high temperature gas-cooled reactor pebble-bed module (HTR-PM) is underway which aims to demonstrate the claimed inherent safety features and its economic competitiveness [1]. After the HTR-PM is completed, the commercial HTR is planning to be promoted in the future. The HTR-PM uses helium as coolant; meanwhile graphite is used as moderator as well as structural material. Its spherical fuel elements contain thousands of TRISO-coated fuel particles embedded in the A3-3 matrix graphite (MG) which is composed of approximately $71 \mathrm{wt} \%$ natural flake graphite, $18 \mathrm{wt} \%$ artificial graphite, and $11 \mathrm{wt} \%$ phenol resin derived carbon [2]. In a pebble fuel element for HTR-PM, more than $95 \%$ in volume is MG. The MG provides structural support to the fuel, prevents fuel from being damaged, and allows heat transfer from the fuel to the coolant. The performance of MG is crucial for guaranteeing the integrity and safety of the fuel elements. Three steps composed the fabrication process of A3-3 MG or fuel pebbles: preparation of resonated MG powders, cold quasiisostatic molding with or without overcoated fuel particles and lathing, and subsequent heat treatments [2]. The heat treatments include the carbonization process and subsequent high temperature procedure. In the carbonization process, molded green pebbles are heated up to $800^{\circ} \mathrm{C}$ in an inert argon atmosphere furnace to carbonize the phenol resin binder to provide strength [3]. Afterward, the carbonized pebbles are cooled down to room temperature, and then they are lathed to a certain dimension and heated under vacuum to a temperature range of $1900-1950^{\circ} \mathrm{C}$ to purify the surface of pebbles which is commonly dubbed as the high-temperature purification (HTP) process so that their 
TABLE 1: EBC and ash contents of raw materials for A3-3 MG $(\mu \mathrm{g} / \mathrm{g})$.

\begin{tabular}{lccc}
\hline & Natural graphite powder & Artificial graphite powder & Phenol resin \\
\hline EBC & 0.223 & 0.087 & 0.330 \\
Ash contents & 10.0 & 11.5 & 43.0 \\
\hline
\end{tabular}

TABLE 2: Difference in the heat treatment and lathing process of molded green MG pebbles.

\begin{tabular}{lccc}
\hline Molded green MG pebbles & \multicolumn{3}{c}{ Subsequent heat treatment and lathing } \\
& 1st & 2nd & 3rd \\
\hline MG pebbles 1 & Carbonization & HTP & Lathing \\
MG pebbles 2 & Carbonization & Lathing & $/$ \\
MG pebbles 3 & Carbonization & & / \\
\hline
\end{tabular}

oxidation corrosion rate can meet the technical requirement [4]. At present, it takes more than 80 hours to accomplish the whole heat treatment process including carbonization and HTP. If the carbonization and HTP process can be carried out continuously, the total time consumption for the continuous heat treatment can be hopefully reduced to 50 hours or even less, which should significantly increase the efficiency and cut the energy cost. The newly established continuous heat treatment process provides a possibility to meet the manufacture requirement of huge amount of pebble fuel elements for the commercial HTR in the future. If the continuous heat treatment can be applied in the mass production of spherical fuel elements, the pebbles should be lathed after the heat treatment so that their dimensions can satisfy the specification. As mentioned earlier, the HTP process is only to purify the outer layer of the pebbles. The purified surfaces of pebbles are removed by lathing and the newly exposed surface should be considered as unpurified which might lead to the disqualification of the oxidation corrosion rate of the pebbles.

Therefore, the oxidation corrosion rate and corresponding ash content of the pebbles lathed before and after HTP process were compared. As a supplement, the oxidation corrosion rate and ash content of the carbonized pebbles that were not treated by HTP process were measured as well. In general, other properties of the carbonized pebbles should be modified by the HTP treatment. However, in the past years, there were no reports on the changes of property and microstructure of pebbles in the HTP process. In order to further investigate the effects of HTP process on the comprehensive properties of pebbles, other mechanical and thermal properties such as crush strength, thermal diffusivity and conductivity, coefficient of thermal expansion (CTE), and erosion rate of pebbles before and after the HTP process are measured. Furthermore, the microstructure features such as the impurity element contents, dimensions and corresponding density, pore information, and degrees of graphitization of pebbles before and after HTP process are characterized as well.

\section{Experimental}

2.1. Preparation of Specimens. Since more than $95 \%$ in volume of fuel element pebbles is composed of $\mathrm{MG}$, the comprehensive properties of fuel pebbles are commonly characterized with MG or MG pebbles instead of the fuel elements. Batches of A3-3 MG pebbles were prepared in INET [2] with qualified raw materials such as natural flake graphite powder, artificial graphite powder, and phenol resin as the binder. The mixing ratio was $64: 16: 20$ by weight, respectively. Table 1 displays the equivalent Boron contents (EBC) and ash contents of the raw materials. The raw materials with high purity are crucial to guarantee the lower ash content and oxidation corrosion rate of the prepared MG pebbles.

As shown in Table 2, three batches of MG pebbles were prepared to fulfill the researches in this study. The difference among the pebbles lay in the heat treatment and lathing process. For MG pebbles 1, at first the molded green pebbles were carbonized, and then the carbonized pebbles were lathed to a certain dimension. Finally, the lathed pebbles were treated with HTP process. The manufacture process of MG pebbles 1 strictly complied with the current manufacture process for fuel elements and MG pebbles [2]. For MG pebbles 2, the pebbles were finally lathed after the pebbles were treated with carbonization and HTP process. And for MG pebbles 3, the pebbles were just carbonized and lathed, and did not suffer the HTP treatment to make a comparison with MG pebbles 1 .

All the specimens in this study were machined in lubricant-free condition and using metal-free tools. As shown in Figure 1, three different orthogonal directions in the pebbles, parallel and perpendicular to the molding direction, are defined as axial (AX) and transverse (TR), respectively. According to the quasi-isostatic molding method, the two transverse directions are commonly considered identical. Multiple specimen types, shapes, and orientations were machined from multiple pebbles. The specimens for the test of CET, thermal diffusivity, and conductivity were machined with two orthogonal orientations, specimen length in the axial and transverse directions. The axial and transverse crush 
TABLE 3: Characteristics of specimens of MG.

\begin{tabular}{|c|c|c|c|c|}
\hline Property & Shape & Orientation & Dimension $(\mathrm{mm})$ & Amount of specimens \\
\hline \multirow{2}{*}{ Crush strength } & \multirow{2}{*}{ Pebble } & Axial & \multirow{2}{*}{$r=59.6-60.2$} & 5 \\
\hline & & Transverse & & 5 \\
\hline \multirow{2}{*}{ Thermal diffusivity and conductivity } & \multirow{2}{*}{ Cylinder } & Axial & \multirow{2}{*}{$\varnothing 12.7 \times 2$} & 3 \\
\hline & & Transverse & & 3 \\
\hline \multirow{2}{*}{$\mathrm{CTE}$ and its anisotropy $\left(20-500^{\circ} \mathrm{C}\right)$} & \multirow{2}{*}{ Cylinder } & Axial & \multirow{2}{*}{$\emptyset 6 \times 25$} & 3 \\
\hline & & Transverse & & 3 \\
\hline Oxidation corrosion rate & Pebble & Null & $r=59.6-60.2$ & 3 \\
\hline Ash content & Pebble & Null & $r=59.6-60.2$ & 2 \\
\hline Erosion rate & Pebble & Null & $r=59.6-60.2$ & 20 \\
\hline Number of drops & Pebble & Null & $r=59.6-60.2$ & 5 \\
\hline
\end{tabular}

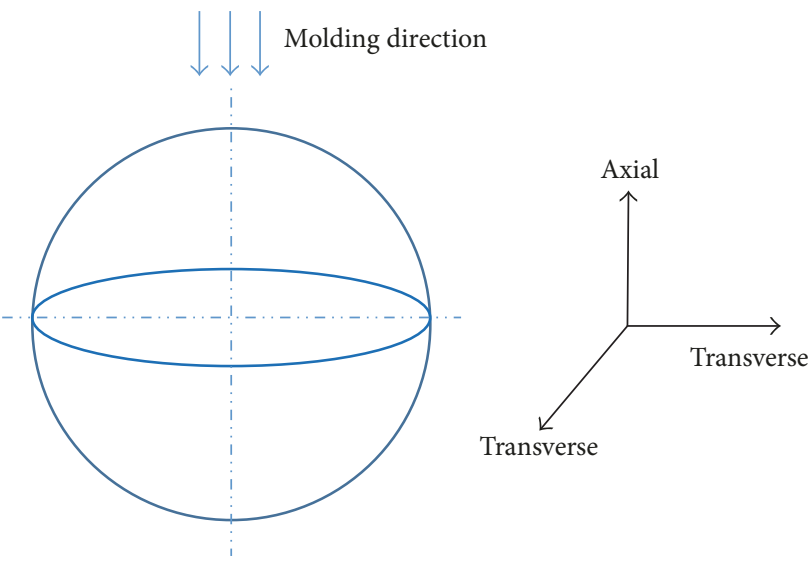

FIGURE 1: Schematic and direction definition for the A3-3 MG pebbles.

strengths of the MG pebbles were tested as well. MG pebbles were used to measure their oxidation corrosion rate, erosion rate, ash contents, and corresponding impurity element contents. The specimens for the microstructure characterization were machined randomly in the MG pebbles. Table 3 presents the exact amounts, orientations, and dimensions of the MG specimens for each property measurement.

\subsection{Property Measurements}

2.2.1. Mechanical Properties. The crush strengths of MG pebbles were tested by a Shimadzu AG-X100 universal testing machine with a maximum load of $100 \mathrm{kN}$ at loading speed of $1 \mathrm{~mm} / \mathrm{min}$. Pebble was compressed within two flat steel contact blocks to guarantee the point-to-point contact between the pebble and the contact blocks.

2.2.2. Thermal Properties. The thermal diffusivity $(\alpha)$ was measured using a Netszch LFA457 thermal flash system. Thermal conductivity $(K)$ values were then estimated utilizing the following equation:

$$
K=\alpha \cdot \rho \cdot C,
$$

where $C$ is the specific heat and $\rho$ is the density of MG. The specific heat for a given temperature was calculated using
Kelly and Taylor's relationship [5]. The thermal expansion behavior was determined by a Netszch Dilatometry $402 \mathrm{CD}$. A heating rate of $5^{\circ} \mathrm{C} / \mathrm{min}$ to $600^{\circ} \mathrm{C}$ was applied with the dilatation measured from room temperature to $500^{\circ} \mathrm{C}$. The sample chamber was maintained under argon during the experiments. The specimen was placed within an alumina sample holder, which was fixed at one end, and an alumina push rod was brought to rest at the other end of the sample. The push rod was fixed to an LVDT, which produces a voltage directly proportional to the displacement. This recorded voltage was corrected for the expansion of the alumina sample holder and push rod. For all specimens, the relative length change on the first heating cycle was measured. The average CTE values between $\mathrm{RT}-500^{\circ} \mathrm{C}$ and $\alpha(\mathrm{RT}-500)$ were calculated from the following:

$$
\alpha(\mathrm{RT}-500)=\frac{\Delta L}{L_{0}} \frac{1}{(500-\mathrm{RT})},
$$

where $\Delta L / L_{0}$ is the relative length change of the specimen over the temperature range of RT to $500^{\circ} \mathrm{C}$. The anisotropy of MG is defined as the ratio of the axial CTE to the transverse one. The thermal gravimetric analysis (TGA) of the carbonized MG was analyzed using Simultaneous Thermal Analyzer (STA 449F3, Netzsch, Germany) to monitor the changes of weight (balance sensitivity, $1 \mu \mathrm{g}$ ) and temperature (temperature sensitivity, $0.1^{\circ} \mathrm{C}$ ). The specimen was heated up from room temperature to $1400^{\circ} \mathrm{C}$ at $10^{\circ} \mathrm{C} / \mathrm{min}$ in flowing Argon (99.999\% purity, $60 \mathrm{ml} / \mathrm{min}$ ).

2.2.3. Other Properties. In the test of corrosion rate of MG, each MG pebble was put into a horizontal tube oven and oxidized at $1000^{\circ} \mathrm{C}$ for 10 hours with the gas flow rate of $80 \mathrm{~L} /$ hour. The oxidant gas included $99 \%$ helium and $1 \%$ water vapor in volume. Three pebbles were oxidized and the average was taken as the corrosion rate of MG. The erosion rate of MG was tested in a home-made apparatus which was mainly composed of a cylinder chamber. Twenty MG pebbles were put into the chamber and then the chamber rotated horizontally at a certain speed for 100 hours. The average erosion rate of the MG pebbles could be calculated by comparing their weight differences before and after erosion. 
TABLE 4: Oxidation corrosion rate and ash content of MG pebbles lathed before and after HTP.

\begin{tabular}{|c|c|c|c|c|c|c|c|}
\hline \multirow{2}{*}{ Samples } & \multicolumn{2}{|c|}{ MG pebbles 1} & \multicolumn{2}{|c|}{ MG pebbles 2} & \multicolumn{2}{|c|}{ MG pebbles 3} & \multirow{2}{*}{ Specification } \\
\hline & Average & Deviation & Average & Deviation & Average & Deviation & \\
\hline Oxidation corrosion rate $\left(\mathrm{mg} \cdot \mathrm{cm}^{-2} \mathrm{~h}^{-1}\right)$ & 0.48 & 0.03 & 0.50 & 0.04 & 1.55 & 0.01 & $\leqslant 1.3$ \\
\hline Ash content (ppm) & 15.15 & 0.35 & 15.80 & 0.46 & 31.7 & 2.12 & $\leqslant 300$ \\
\hline
\end{tabular}

\subsection{Microstructure Characterizations}

2.3.1. Ash Contents and Impurities. MG pebbles were burned in the Pt crucible in a muffle oven until the weight of the crucible was constant. Two pebbles were used to run the parallel measurement. The ash contents of MG can be obtained by

$$
\text { Ash contents }=\frac{\left(W_{1}-W_{0}\right)}{W_{\mathrm{p}}} * 100 \%,
$$

where $W_{0}$ was the initial weight of Pt crucible and $W_{1}$ was the stable weight of Pt crucible after the pebble was burned off and $W_{\mathrm{p}}$ was the original weight of the pebble before burning off. The residual ashes in the Pt crucibles were completely dissolved by microwave digestion with the combination of hydrochloric acid, nitric acid, and hydrofluoric acid. The resultant solutions were further analyzed by Inductively Coupled Plasma Mass Spectrometry (ICP-MS, Nexion 300, Perkin Elmer, USA) or Inductively Coupled Plasma Optical Emission Spectrometer (ICP-OES, Optima 8000DV, Perkin Elmer, USA) to characterize the exact impurity element contents of MG.

2.3.2. Raman Spectroscopy. Raman spectroscopy is an important method to characterize the microstructure of graphite materials, especially the analysis of structural defects and in-plane crystallite size. In this study, three Raman spectra were collected by a laser (532.1 nm wavelength, $50 \mathrm{~mW}$ ) on three different spots on the MG sample surface, with a spatial and spectrum resolution less than $1 \mu \mathrm{m}$ and $0.65 \mathrm{~cm}^{-1}$, respectively. Since the intensity of the defect-deduced $\mathrm{D}$ band (at $\sim 1350 \mathrm{~cm}^{-1}$ ) compared with the $\mathrm{G}$ band (at $\sim 1580 \mathrm{~cm}^{-1}$ ) depends on the size of graphite crystals, the in-plane crystalline size of $\mathrm{MG}$ is calculated using the following equation $[6,7]$ :

$$
L_{\mathrm{a}}(\mathrm{nm})=\left(2.4 \times 10^{-10}\right) \lambda_{\text {laser }}^{4}\left(\frac{I_{\mathrm{G}}}{I_{\mathrm{D}}}\right)
$$

where $\lambda_{\text {laser }}=532.1 \mathrm{~nm}$. To compare $L_{\mathrm{a}}$ between the MG before and after HTP process, the calculated $L_{\mathrm{a}}$ of three different spots was averaged.

2.3.3. Mercury Porosimetry. The measurement of porosity and pore size distribution in the MG by the method of Mercury Porosimetry was strictly complied with the ASTM D4404-10 [8]. The volume of the pores was determined by measuring the volume of mercury intruding the pores at various pressures. The absolute pressures were converted into apparent intruded pore size diameters by the following equation:

$$
d=\frac{-4 \gamma \cos \theta}{P}
$$

where $d$ is apparent diameter of the pore being intruded, $\gamma$ is the surface tension of the mercury ( 485 dynes $/ \mathrm{cm}$ ), $\theta$ is the contact angle between mercury and $\mathrm{MG}\left(130^{\circ}\right)$, and $P$ is the absolute pressure causing the intrusion.

2.3.4. Morphology Characterization. The surface of the pebbles after erosion was characterized using optical microscopy (Stemi 2000-C, Carl Zeiss, Germany) with the magnification of $10 x$.

\section{Results and Discussions}

3.1. Oxidation Corrosion Rate and Ash Content. Table 4 displays the average oxidation corrosion rate and ash content of MG pebbles 1-3. As expected, the oxidation corrosion rate and ash content of MG pebbles 1 satisfy the specifications. Meanwhile, there is no significant difference of the corrosion rate and ash content between the MG pebbles lathed before and after HTP. The oxidation corrosion rate and ash content of MG pebbles lathed after HTP are qualified as well. It can be concluded that the HTP process is to not only purify the surface of the pebbles but also purify the entire pebbles from inside to outside, which ensures the probability of continuous heat treatment of MG pebbles and spherical fuel elements in their future mass production.

However, the oxidation corrosion rate of MG pebbles 3 that did not suffer the HTP was $1.55 \mathrm{mg} /\left(\mathrm{cm}^{2} \cdot \mathrm{h}\right)$, which did not satisfy the specification. After the HTP process, the oxidation corrosion rate of $\mathrm{MG}$, that is, $\mathrm{MG}$ pebbles 1 , significantly decreased. The average oxidation corrosion rate of MG pebbles 3 was more than 3 times higher than that of MG pebbles 1 which was $0.41 \mathrm{mg} /\left(\mathrm{cm}^{2} \cdot \mathrm{h}\right)$. Reviewing literature, the oxidation corrosion rate of graphite was not only determined by its degree of graphitization but also influenced by the content of impurity elements such as the $\mathrm{Fe}, \mathrm{Cr}$, and $\mathrm{Co}$ that would act as the catalysts in the oxidation process in the MG $[9,10]$. As shown in Table 4, the ash content of MG pebbles treated with and without HTP both met the requirement of specification. Through the HTP process, the ash content of MG pebbles 3 decreased around $50 \%$ from $31.70 \mathrm{ppm}$ to $15.15 \mathrm{ppm}$ of MG pebbles 1 . The carbonized MG pebbles 3 with high purity was further purified as expected which was considered beneficial to improve the oxidation resistance of MG. Thus, the HTP process had remarkable influences on the oxidation rate and 
TABLE 5: Weight and volume changes of MG during the heat treatment process.

\begin{tabular}{lcc}
\hline Changes (1- after/before) & Carbonization/\% & HTP/\% \\
\hline Weight & 10.61 & 0.29 \\
Axial dimension & 1.93 & 0.35 \\
Transverse dimension & 1.31 & 0.35 \\
Volume & 4.48 & 1.04 \\
\hline
\end{tabular}

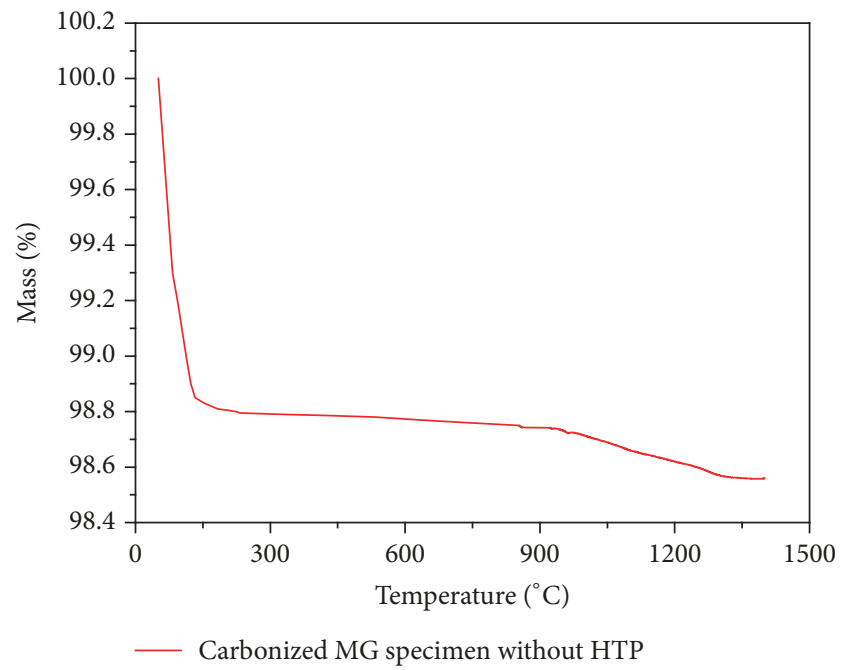

FIGURE 2: Mass changes of carbonized MG sample by TGA.

ash content of MG pebbles. In order to further explore the effects of HTP process on other properties of carbonized MG pebbles and reveal the underlying mechanism, multiple mechanical and thermal properties and microstructures of MG pebbles treated with and without HTP were analyzed and characterized as mentioned in the following.

3.2. Weight and Dimensional Changes. Table 5 shows the weight and volume changes of MG during the process of carbonization and HTP. The weight changes during the carbonization and HTP is $10.61 \%$. The significant weight loss of MG during the carbonization attributes to the decomposition of the binder of phenol resin [11]. After the carbonization, the phenol resin transforms into 3-dimensional network of phenol resin derived carbon that makes the matrix graphite have certain strength. As a result, the total volumetric shrinkage of MG during the carbonization is approximately $4.48 \%$. When the carbonized MG pebbles was treated at $1900^{\circ} \mathrm{C}$ for further purification, a slight weight loss of $0.29 \%$ was observed. Based on the TGA result shown in Figure 2, the rapid weight loss below $150^{\circ} \mathrm{C}$ of the carbonized MG without HTP is due to the loss of absorbed water in the MG sample. Then the mass of the sample remains almost constant at less than $900^{\circ} \mathrm{C}$. As the temperature continues to rise, a slight weight loss occurs until the temperature reaches around $1300^{\circ} \mathrm{C}$. The minute quantity of weight change in the range of $900-1300^{\circ} \mathrm{C}$ ascribes to the further decomposition of a tiny amount of organic functional groups such as carbon-hydrogen bond remaining on the surface of matrix graphite [4].
Meanwhile a tiny amount of gas with small molecule such as hydrogen are released. The mass loss in the TGA from 900 to $1300^{\circ} \mathrm{C}$ is less than $0.3 \%$ that is consistent with the weight loss measured results of $0.29 \%$ during the HTP process. Some trace metal impurities are removed during the HTP process as well. The carbonized MG further shrinks volumetrically for $1.04 \%$ during the HTP process. The ratio of changes of volume to weight during the processes of carbonization and HTP of MG pebbles are 0.42 and 3.59, respectively. The ratio of the HTP process being much larger than that of the carbonization process indicates the different underlying mechanism between the carbonization and HTP. In the HTP process, the large ratio of volume to weight changes of MG is not only caused by the tiny weight loss but also probably ascribed to the microstructural changes of the phenol resin derived carbon acting as the binder in the MG.

3.3. Properties Evaluation. The multiple mechanical and thermal properties of MG treated with and without HTP process (MG pebbles 1 and 3 separately) were shown in Table 6. The comprehensive properties of MG pebbles 1 totally satisfied the specifications. However, some properties such as the crush strength, erosion rate, and oxidation corrosion rate of MG pebbles 3 without HTP were not qualified.

3.3.1. Mechanical Properties. After being treated with the HTP process, the bulk density of the MG increased slightly for $0.23 \%$ from 1.749 to $1.753 \mathrm{~g} / \mathrm{cm}^{3}$. Nevertheless, comparing with those of MG without HTP, the average axial and transverse crush strengths of MG treated with HTP increased significantly for $19.33 \%$ and $12.34 \%$, respectively. Meanwhile, the average erosion rate of MG pebbles with HTP was only around $1 / 6$ of that of MG without HTP. The underlying microstructure upgradation and slight increase of bulk density of MG treated under high temperature could be considered as the main influence factors, which led to the significant improvements of crush strength and antierosion rate of MG through the HTP process. The comparison of the appearances of the pebbles with and without HTP suffering the erosion were shown in Figure 3. The surfaces of the pebbles treated with HTP after erosion were homogeneously smooth and bright; on the contrary, many inhomogeneous defects distributed in the surfaces of the pebbles without HTP after erosion. Optical images with 10x magnification showed that there were many tiny holes in the defect area of pebbles without HTP. The holes on the surface were caused by the peeling off the fillers, which indicated the poor interfacial forces between the graphite fillers and binders in the MG. The smooth surface of pebbles treated with HTP after erosion exhibited strong binding force between the fillers and binders 
TABLE 6: Comparison of properties of MG treat with and without HTP.

\begin{tabular}{|c|c|c|c|c|c|}
\hline Property & $\begin{array}{l}\text { Average of MG } \\
\text { without HTP }\end{array}$ & $\begin{array}{c}\text { Deviation } \\
\text { of MG } \\
\text { without } \\
\text { HTP }\end{array}$ & $\begin{array}{c}\text { Average of } \\
\text { MG with } \\
\text { HTP }\end{array}$ & $\begin{array}{c}\text { Deviation } \\
\text { of MG } \\
\text { with HTP }\end{array}$ & Specification \\
\hline Bulk density $\left(\mathrm{g} \cdot \mathrm{cm}^{-3}\right)$ & 1.749 & 0.004 & 1.753 & 0.006 & $1.70-1.77$ \\
\hline $\begin{array}{l}\text { Crush strength (AX/TR) } \\
(\mathrm{kN})\end{array}$ & $19.86 / 17.98$ & $0.78 / 0.35$ & $23.78 / 20.26$ & $0.32 / 0.57$ & $\geqslant 18.0$ \\
\hline $\begin{array}{l}\text { Thermal conductivity } \\
(\mathrm{AX} / \mathrm{TR})\left(\mathrm{W} \cdot \mathrm{m}^{-1} \mathrm{~K}^{-1}\right)\end{array}$ & $31.83 / 36.97$ & $0.57 / 0.81$ & $37.36 / 39.74$ & $0.95 / 0.76$ & $\geqslant 25.0$ \\
\hline CTE $(\mathrm{AX} / \mathrm{TR})\left(10^{-6} \mathrm{~K}^{-1}\right)$ & $4.74 / 4.15$ & $0.04 / 0.08$ & $3.69 / 3.07$ & $0.08 / 0.27$ & Null \\
\hline Anisotropy & 1.140 & 0.025 & 1.162 & 0.074 & $\leqslant 1.3$ \\
\hline $\begin{array}{l}\text { Oxidation corrosion rate } \\
\left(\mathrm{mg} \cdot \mathrm{cm}^{-2} \mathrm{~h}^{-1}\right)\end{array}$ & 1.55 & 0.01 & 0.48 & 0.03 & $\leqslant 1.3$ \\
\hline $\begin{array}{l}\text { Erosion rate }\left(\mathrm{mg} \cdot \mathrm{h}^{-1} \text { per }\right. \\
\text { pebble) }\end{array}$ & 14.23 & 0.227 & 2.41 & 0.028 & $\leqslant 6.0$ \\
\hline Number of drops ${ }^{c}$ & Qualified & & Qualified & & $\geqslant 50$ \\
\hline Ash content (ppm) & 31.70 & 2.12 & 15.15 & 0.35 & $\leqslant 300$ \\
\hline
\end{tabular}

${ }^{a}$ The value of thermal conductivity at $1000^{\circ} \mathrm{C} .{ }^{b} 1000^{\circ} \mathrm{C}, 10 \mathrm{~h}$; atmosphere is $\mathrm{He}+1 \mathrm{vol} \% \mathrm{H}_{2} \mathrm{O}$. ${ }^{\mathrm{c}}$ Numbers of drops from a height of $4 \mathrm{~m}$ onto the matrix sphere bed before break.

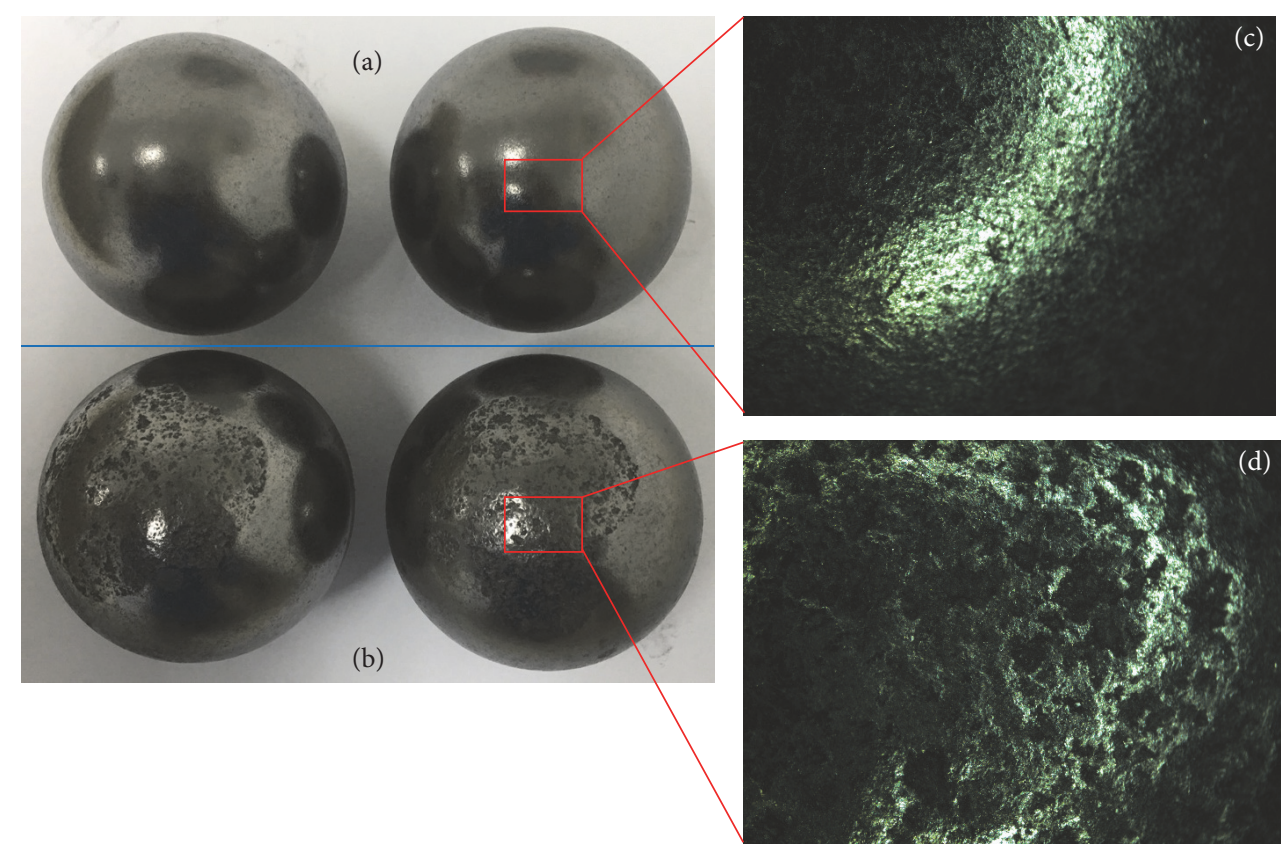

FIGURE 3: Morphology of surface of the MG pebbles after erosion. (a) MG pebbles 1 with HTP; (b) MG pebbles 3 without HTP; (c) and (d) magnified (10x).

in the MG, which coincided well with the improvement of the mechanical strength of MG.

3.3.2. Thermal Properties. The average axial and transverse thermal conductivities with HTP were $17.19 \%$ and $7.38 \%$, respectively higher than those of MG without HTP which further proved the improvement of microstructure of $\mathrm{MG}$ through the HTP to a certain extent [12]. The axial and transverse CTE of MG decreased around $22 \%$ and $26 \%$ after the treatment of HTP process. However, the anisotropy of CTE of MG remained almost constant through the HTP process. The improvement of thermal conductivity and mechanical strength and the decrease of CTE through the HTP process are beneficial to enhance the thermal shock resistance of MG, which is vitally important for the integrity and safety of pebble fuel elements during their cycle in the operated HTGRs.

To further investigate the effects of HTP process on the properties of MG, the thermal diffusivity of MG with and without HTP was measured at various temperatures. Figure 4 
TABLE 7: Quantitative analysis of Raman spectra for phenol resin derived carbon with and without HTP.

\begin{tabular}{|c|c|c|c|c|c|c|c|}
\hline Sample & Spot & $I_{\mathrm{G}}$ & $I_{\mathrm{D}}$ & $I_{\mathrm{G}} / I_{\mathrm{D}}$ & Mean $I_{\mathrm{G}} / I_{\mathrm{D}}$ & $L_{\mathrm{a}}(\mathrm{nm})$ & Mean $L_{\mathrm{a}}(\mathrm{nm})$ \\
\hline \multirow{3}{*}{ Without HTP } & 1 & 2550 & 2333 & 1.093 & \multirow{3}{*}{1.097} & 21.0 & \multirow{3}{*}{$21.1 \pm 0.8$} \\
\hline & 2 & 2608 & 2419 & 1.078 & & 20.7 & \\
\hline & 3 & 2655 & 2374 & 1.118 & & 21.5 & \\
\hline \multirow{3}{*}{ With HTP } & 1 & 806 & 529 & 1.524 & \multirow{3}{*}{1.551} & 29.3 & \multirow{3}{*}{$29.9 \pm 1.0$} \\
\hline & 2 & 791 & 508 & 1.557 & & 30.0 & \\
\hline & 3 & 791 & 503 & 1.573 & & 30.3 & \\
\hline
\end{tabular}

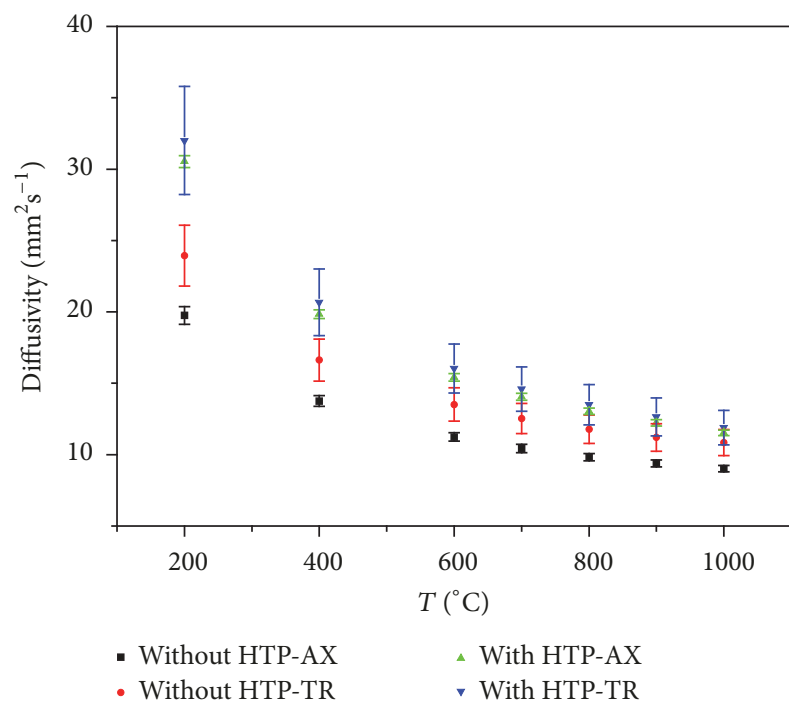

FIGURE 4: Axial and transverse thermal diffusivity of MG without and with HTP process.

shows the average axial and transverse thermal diffusivities and relative standard deviations of MG with and without the HTP process. In general, the thermal diffusivity of MG decreased gradually with the increasing temperature due to the well-known phonon-phonon scattering in ceramic materials [13]. It is obvious that through the HTP process both the axial and transverse thermal diffusivity of MG increased to a different extent, which is due to the improvement of degree of graphitization of the binder in the HTP as mentioned above. The diffusivity differences between the MG with and without HTP became less and less with the increasing measured temperature. The transverse diffusivities of MG without HTP were higher than the axial ones at different temperatures. However, the axial diffusivities of $\mathrm{MG}$ with HTP were close to the transverse ones, especially at higher temperatures. For example, the average transverse diffusivity of MG before $\mathrm{HTP}$ at $400^{\circ} \mathrm{C}$ was $16.63 \mathrm{~mm}^{2} / \mathrm{s}$ which was $20.64 \%$ higher than the axial one. Meanwhile, the average transverse diffusivity of MG after HTP at $400^{\circ} \mathrm{C}$ was $20.68 \mathrm{~mm}^{2} / \mathrm{s}$ which was only $3.83 \%$ higher than the axial one. The substantial divergence between axial and transverse diffusivities of MG without HTP was probably owing to the texture orientation in the microstructure formed in the quasi-static molding process. The minor difference between axial and transverse diffusivities, that is, the anisotropy of diffusivity of MG with HTP, indicated that the microstructure and corresponding texture of MG were upgraded during the HTP process.

3.4. Raman Spectroscopy Analysis. Raman spectroscopy is a noncontacting, nondestructive, and quick measurement method to characterize the structure of graphitic materials, in particular providing valuable information about defects and in-plane crystallite size $[5,6]$. As noted earlier, the MG is composed of natural flake graphite, artificial graphite, and phenol resin derived carbon. The structure of the completely graphitized natural and artificial graphite should not change during the heat treatment. In order to avoid the interference of natural and artificial graphite in the test of Raman spectrum, the binder of phenol resin derived carbon treated with and without HTP was used instead of the MG. To acquire a more representative value, three Raman spectra were collected from three different spots for the carbon specimens with and without HTP, respectively.

Figure 5 shows the Raman spectra in the $1000-3000 \mathrm{~cm}^{-1}$ wavelength shift range of phenol resin derived carbon with and without HTP process. For carbon materials, D band (at $\sim 1350 \mathrm{~cm}^{-1}$ ) corresponds to the first-order defect-induced Raman features. G band (at $\sim 1580 \mathrm{~cm}^{-1}$ ) corresponds to E2gmode lattice vibration in $\mathrm{sp}^{2}$ carbon network. The $\mathrm{D}$ band and $G$ band are sharpened in the Raman spectra and the mean ratio of $I_{\mathrm{G}}$ to $I_{\mathrm{D}}$ increases nearly $50 \%$ with HTP as shown in Table 7, which illustrates a better ordered carbon and improvement of degree of graphitization [14, 15]. After being treated with the HTP process, the phenol resin derived carbon exhibits a higher degree of graphitization, more ordered structure, and larger crystallite size of $L_{\mathrm{a}}$, which is beneficial to improve the comprehensive properties of the MG, especially the antioxidation corrosion rate. In addition, an intense line $G^{\prime}$ band (at $2700 \mathrm{~cm}^{-1}$ ) appears in the second-order Raman spectrum of carbon treated with HTP. The $\mathrm{G}^{\prime}$ band is more obvious from the background with HTP, indicating that this line is more sensitive to graphitizationordered structure induced by high temperature than the firstorder lines.

3.5. Porosity. Figure 6 presents the pore information of MG with and without HTP process measured by Mercury Porosimetry. As shown in Figure 6, the pore size in the MG increased slightly with HTP because the residual small amount of $\mathrm{C}-\mathrm{H}$ bonds decomposed at higher temperature as mentioned above. As a result, the pore cumulative volume of 


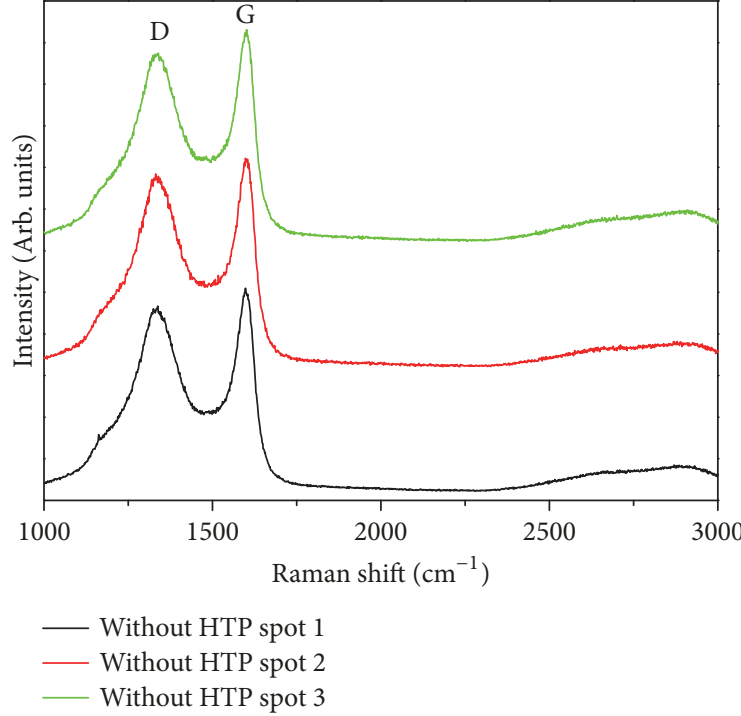

(a)

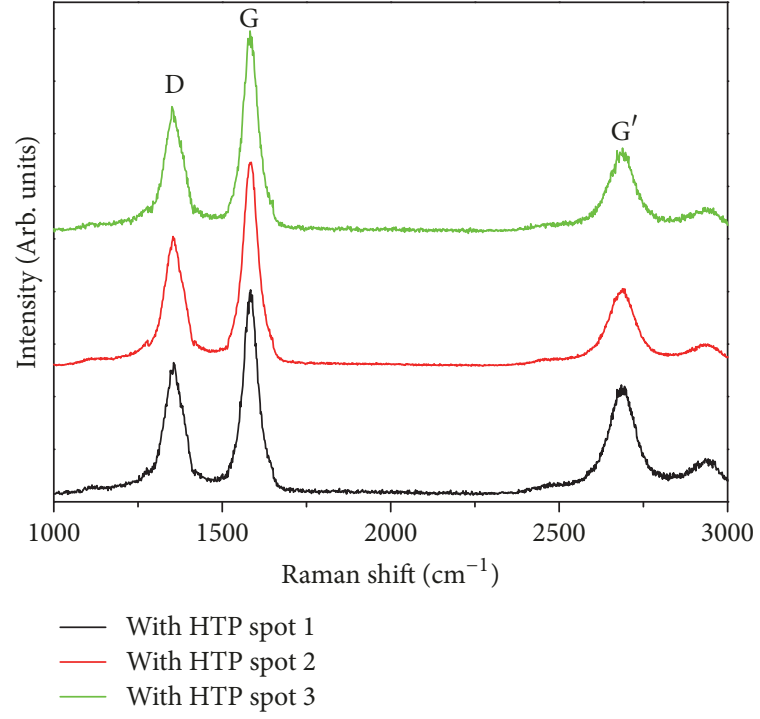

(b)

FIGURE 5: Raman spectra from three different spots on the phenol resin derived carbon without HTP (a) and with HTP (b).

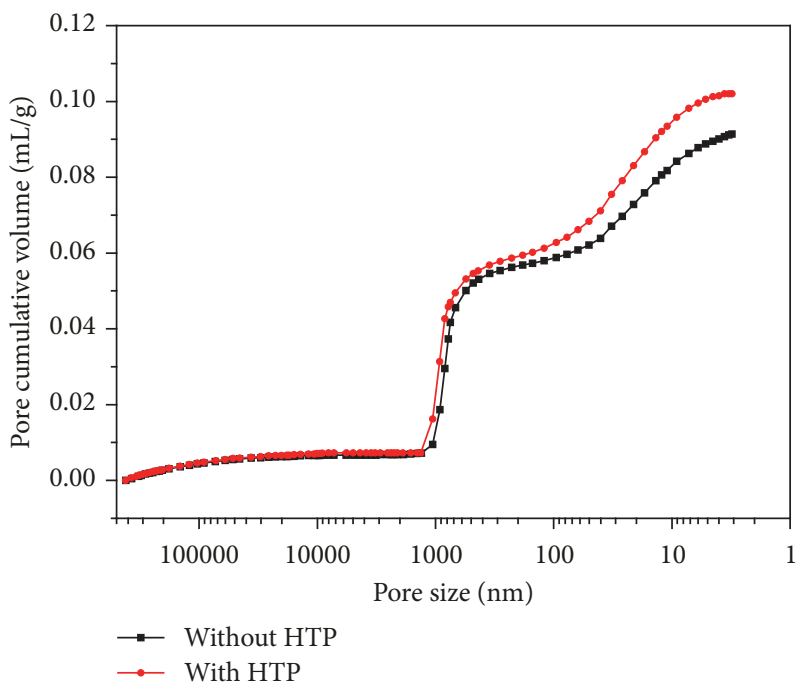

FIGURE 6: Pore information of MG with and without HTP measured by Mercury Porosimetry.

MG with HTP was higher than that of MG without HTP. The difference became even more significant when the intruding pore size was smaller than $50 \mathrm{~nm}$. The measured porosities of MG without and with HTP were $15.20 \%$ and $16.99 \%$, respectively. Meanwhile, the skeletal density of MG improved from 2.06 to $2.12 \mathrm{~g} / \mathrm{cm}^{3}$ through the HTP process, which led to the slight increase of bulk density as mentioned before.

The release of gas from the decomposition of residual organic functional groups at higher temperature certainly induced additional porosity in small pores and increased the skeletal density in the meantime. In addition, the improvement of degree of graphitization may cause shrinkage and increase the density. The increase of density of MG through the HTP process is beneficial to the improvement of comprehensive properties, especially the mechanical properties of MG. On the other hand, there have been reports that Mercury Porosimetry itself can damage the sample at very high pressures $[16,17]$. Pores smaller than $\sim 50 \mathrm{~nm}$ and in particular an increase in pores at this range when apparent from mercury intrusion should be interpreted with caution. Considering that the graphite is a brittle material and graphitization make the MG more brittle, the significant increase of porosity in pores less than $50 \mathrm{~nm}$ may be ascribed to the damage of graphite microstructure caused by the high intruding pressures.

3.6. Impurity Element Contents. As listed in Table 8, the ash contents of MG without and with HTP were 31.70 and 15.15 ppm, respectively. After being treated with the HTP process, the carbonized MG with qualified ash content was further purified to lower impurity levels. In order to find out the detailed changes of impurity elements in the HTP process, the content of more than 30 elements was measured by the methods of ICP-OES or ICP-MS. Table 8 showed the contents of some impurity elements of MG without and with HTP process. The major impurities in carbonized MG were Fe (7.967 ppm), Cr (3.203 ppm), Ca (2.555 ppm), Al (1.741 ppm), and $\mathrm{Ni}(1.622 \mathrm{ppm})$. The impurities in the carbonized MG may act as the catalysts and accelerate the oxidation during the measurement of oxidation corrosion rate. After being treated with the HTP process, the remaining impurities were Fe $(2.373 \mathrm{ppm}), \mathrm{Ca}(2.103 \mathrm{ppm})$, and $\mathrm{Cr}(1.190 \mathrm{ppm})$. The decrease of contents of impurity elements, especially the transition metal elements, and the improvement of the degree of graphitization of MG through the HTP process result in the lower oxidation corrosion rate of the MG with HTP as shown in Tables 4 and 6. 
TABLE 8: Contents of some impurity elements of MG with and without HTP process.

\begin{tabular}{lccc}
\hline Element & Apparatus & Without HTP/ppm & With HTP/ppm \\
\hline $\mathrm{Al}$ & ICP-OES & 1.741 & 0.687 \\
$\mathrm{Ca}$ & ICP-OES & 2.555 & 2.103 \\
$\mathrm{~V}$ & ICP-MS & 0.306 & 0.194 \\
$\mathrm{Cr}$ & ICP-OES & 3.203 & 1.190 \\
$\mathrm{Fe}$ & ICP-OES & 7.967 & 2.373 \\
$\mathrm{Mo}$ & ICP-OES & 0.232 & 0.006 \\
$\mathrm{Ni}$ & ICP-OES & 1.622 & 0.556 \\
\hline
\end{tabular}

\section{Conclusions}

Multiple properties of A3-3 MG related to the HTP process were investigated. The oxidation corrosion rate and ash content of MG pebbles lathed before and after HTP were almost identical, which indicated the HTP process was to purify not only the surface of MG pebbles, but also the entire MG pebbles. Based on the results, the possibility of continuous heat treatment of pebble fuel elements in their mass production would be greatly improved in the future. Compared with those of MG without HTP whose crush strength, oxidation corrosion rate, and erosion rate were not qualified, the comprehensive properties of MG treated with HTP process were improved at different degree. According to the analysis results of Raman spectra, the degree of graphitization and crystallite size $\left(L_{\mathrm{a}}\right)$ of the binder carbon in the MG was enhanced through the HTP process. As a result, the skeletal density and corresponding bulk density of MG after HTP process were improved although the porosity of MG was slightly increased owing to the decomposition of residual small amount of organic functional groups and release of gas under high temperature. The better ordered microstructure and higher density of $\mathrm{MG}$ through the HTP process resulted in the optimization of mechanical strength, thermal conductivity, and antioxidation property. Furthermore, purification of the carbonized MG with high purity under high temperature further reduced the content of impurity elements, especially for the transition metal elements, which was also beneficial to reduce the oxidation corrosion rate of MG obtained with HTP.

\section{Conflicts of Interest}

The authors declare that there are no conflicts of interest regarding the publication of this paper.

\section{Acknowledgments}

Supports from the Chinese National S\&T Major Project (ZX06901), Chinese National Natural Science Foundation (51420105006), and Key Program for International S\&T Cooperation Projects of China (2016YFE0100700) are acknowledged. Also, the helps of Dr. Hongsheng Zhao, Dr. Xiaotong Chen, and Kaihong Zhang from INET, Tsinghu University of Beijing, China, and the helps of Dr. C. I. Contescu from Oak Ridge National Laboratory, USA, are acknowledged.

\section{References}

[1] Z. Zhang, Z. Wu, D. Wang et al., "Current status and technical description of Chinese $2 \times 250 \mathrm{MW}_{t h}$ HTR-PM demonstration plant," Nuclear Engineering and Design, vol. 239, no. 7, pp. 12121219, 2009.

[2] Z. Xiangwen, L. Zhenming, Z. Jie et al., "Preparation of spherical fuel elements for HTR-PM in INET," Nuclear Engineering and Design, vol. 263, pp. 456-461, 2013.

[3] X.-W. Zhou, J. Zhang, Z.-M. Lu, Y.-W. Zou, and Y.-P. Tang, "Study on the carbonization process in the fabrication of pebble fuel elements," Nuclear Engineering and Design, vol. 271, pp. 149153, 2014.

[4] T. Chunhe, Fuel elements for high temperature gas-cooled reactors, Chemical Industry Press, 2007.

[5] B. T. Kelly and R. Taylor, "The thermal properties of graphite," in Chemistry and physics of carbon, P. L. Walker and P. A. Thrower, Eds., vol. 10, pp. 1-140, Dekker, NY, USA, 1973.

[6] M. A. Pimenta, G. Dresselhaus, M. S. Dresselhaus, L. G. Cançado, A. Jorio, and R. Saito, "Studying disorder in graphitebased systems by Raman spectroscopy," Physical Chemistry Chemical Physics, vol. 9, no. 11, pp. 1276-1291, 2007.

[7] G. Zheng, P. Xu, S. Kumar, and A. Todd, "Characterization of structural defects in nuclear graphite IG-110 and NBG-18," Journal of Nuclear Materials, vol. 446, pp. 193-199, 2014.

[8] ASTM, "Standard test method for determination of pore volume and pore volume distribution of soil and rock by mercury intrusion porosimetry," Tech. Rep. ASTM D440410, ASTM International, West Conshohocken, PA, USA, 2010, https://www.astm.org/.

[9] C. I. Contescu, Effect of air oxidation on pore structure development and mechanical properties of nuclear graphite, ORNL/TM2010/197, September 2010.

[10] C. I. Contescu, S. Azad, D. Miller, M. J. Lance, F. S. Baker, and T. D. Burchell, "Practical aspects for characterizing air oxidation of graphite," Journal of Nuclear Materials, vol. 381, no. 1-2, pp. 15-24, 2008.

[11] Y. Yasumasa and K. Koji, "A study on carbonization of phenolformaldehyde resin labelled with deuterium and ${ }^{13} \mathrm{C}$," Carbon, vol. 19, no. 2, pp. 89-94, 1981.

[12] W. Windes, T. Burchell, and M. Carroll, "Graphite technology development plan,” Tech. Rep. 23747, Idaho National Laboratory, Idaho, USA, 2010.

[13] N. Mingo, "Anharmonic phonon flow through molecular-sized junctions," Physical Review B: Condensed Matter and Materials Physics, vol. 74, no. 12, Article ID 125402, 2006.

[14] S. Reich and C. Thomsen, "Raman spectroscopy of graphite," Philosophical Transactions of the Royal Society A: Mathematical, 
Physical \& Engineering Sciences, vol. 362, no. 1824, pp. 22712288, 2004.

[15] A. Li, Z.-K. Ma, H.-H. Song, K. Lu, Z.-J. Liu, and Q.-G. Guo, "Effect of heat treatment temperature on the microstructure and properties of polyimide-based carbon fibers," Xinxing Tan Cailiao/New Carbon Materials, vol. 29, no. 6, pp. 461-466, 2014.

[16] D. J. Baker and J. B. Morris, "Structural damage in graphite occurring during pore size measurements by high pressure mercury," Carbon, vol. 9, no. 5, pp. 687-690, 1971.

[17] J. M. Dickinson and J. W. Shore, "Observations concerning the determination of porosities in graphites," Carbon, vol. 6, no. 6, pp. 937-941, 1968. 

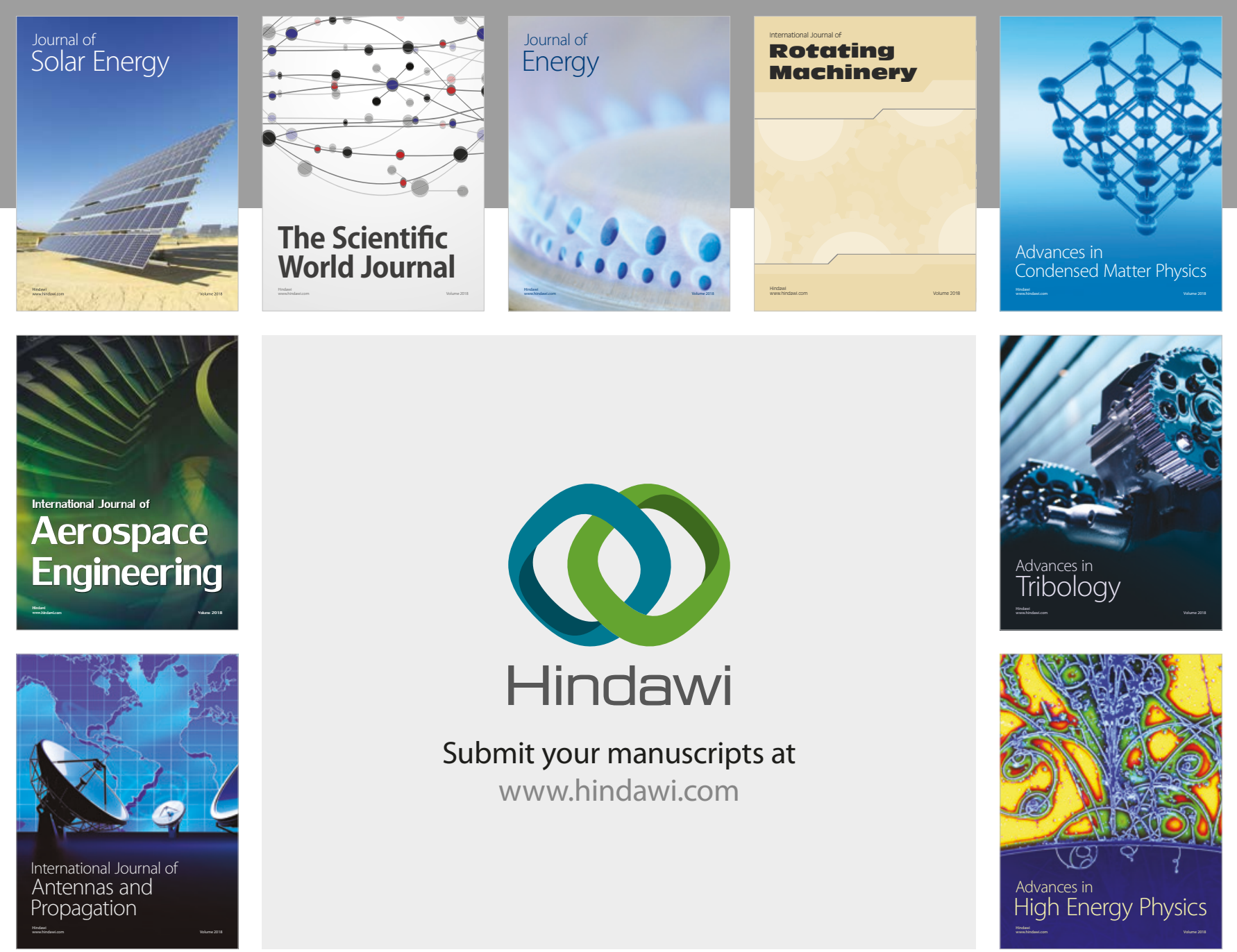

Submit your manuscripts at

www.hindawi.com
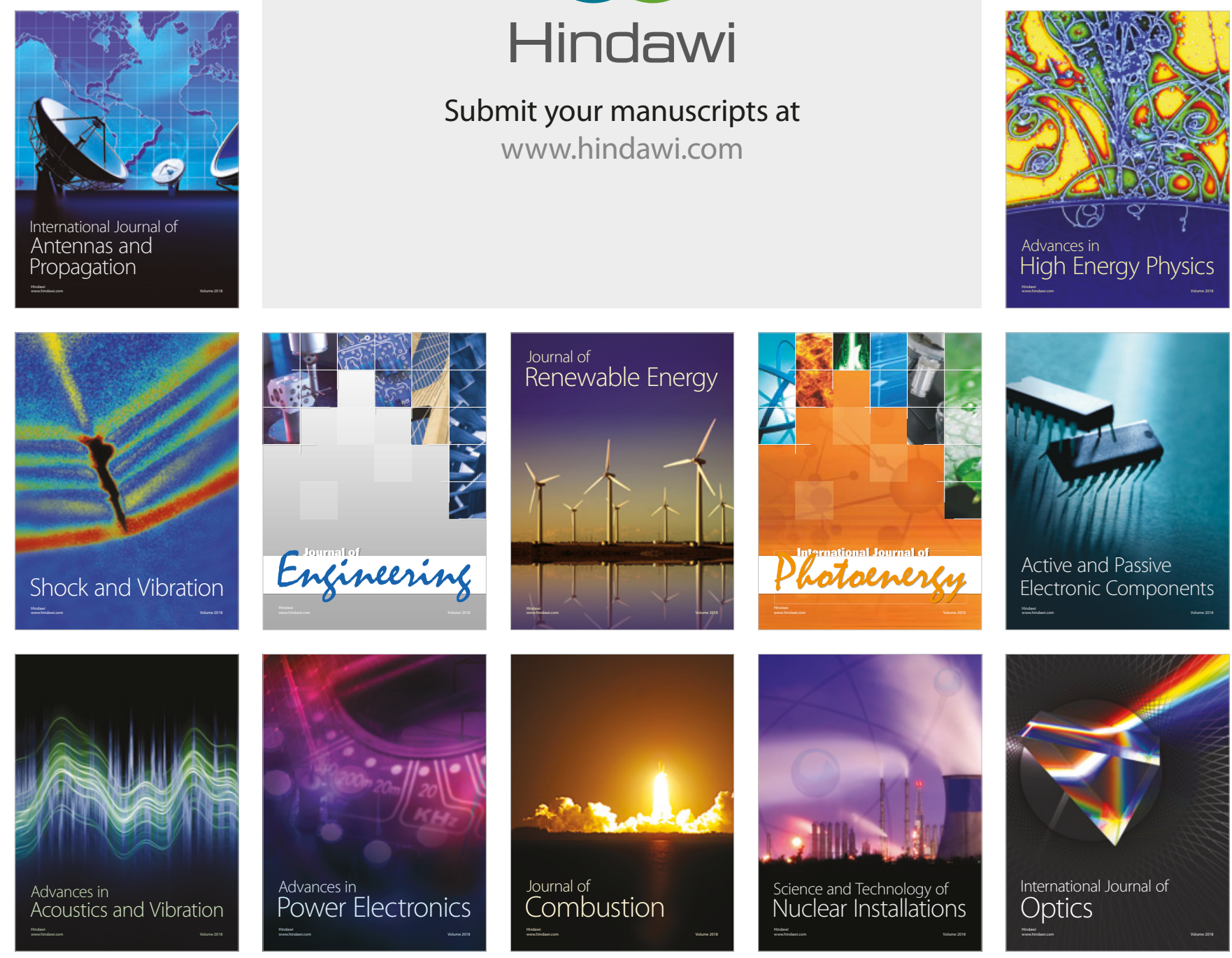